\title{
EXPERIMENTAL BEHAVIOR OF CIRCULAR HSSCFRC FILLED STEEL TUBULAR COLUMNS UNDER AXIAL COMPRESSION
}

\author{
H. Ravi Kumar ${ }^{1}$, K.U.Muthu' ${ }^{2}$, N.S.Kumar ${ }^{3}$ \\ ${ }^{1}$ PhD Scholar, Assistant Professor, Sir M.Visvesvaraya Institute of Technology, Bangalore \\ ${ }^{2}$ Dean, Brindavan college of Engineering, Bangalore \\ ${ }^{3}$ Professor \& Director (R\&D-Civil), Ghousia College of Engineering, Ramanagaram \\ hrkmvit@gmail.com
}

\begin{abstract}
This paper presents an outlook on experimental behavior and a comparison with predicted formula on the behaviour of circular concentrically loaded self-consolidating fibre reinforced concrete filled steel tube columns (HSSCFRC). Forty-five specimens were tested. The main parameters varied in the tests are: (1) percentage of fiber (2) tube diameter or width to wall thickness ratio (D/t from 15 to 25) (3) L/d ratio from 2.97 to 7.04 the results from these predictions were compared with the experimental data. The experimental results) were also validated in this study.
\end{abstract}

Keywords: Self-compacting concrete; Concrete-filled steel tube; axial load behavior; Ultimate capacity.

$* * *$

\section{INTRODUCTION}

Concrete-filled steel tubular (CFST) columns possess excellent earthquake-resistant properties such as high strength, high ductility, and large energy absorption capacity. In recent years, the possibility of using thin-walled HSS columns filled with self-consolidating concrete (SCC), or self-compacting concrete, in practical engineering has been of interest to structural engineers. Self-consolidating concrete, as it is sometimes known, arrived as a revolution in the field of concrete technology The self-compactability of concrete refers to the capability of the concrete to flow under its own weight and fill in the formwork in cast processing. Due to its rheological properties, the disadvantage of vibration can be eliminated while still obtaining good consolidation. Apart from reliability and constructability, advantages such as elimination of noise in processing plants, and the reduction of construction time and labor cost have been cited as arising from the self-consolidation function of SCC. The literature review points out that the reputed investigation of thin walled structural steel sections with SCC fill are less numerous. fibre reinforced concrete (FRC) is used as an in-fill material, as it has greater flexural strength and tensile strength than plain concrete. The purpose of this study was to examine the effects of FRC on the strength and behaviour of composite columns. However it is to be noted that the addition of fibres in the concrete will enhance the load carrying capacity because the infill material has greater flexural strength and tensile strength than plain SCC. Therefore the lack of information on the behaviour of HSS Columns with SCC \& Fibres as infill necessities the need for research in this area The relationship between workability and strength and co-relation between compressive and tensile strength of self compacting concrete have been established in the earlier studies. $(1,2)$.

The present study is an attempt to study the possibility of using high strength self-compacting concrete and steel fibres in thin walled HSS columns. The objectives of present study are: -

1. To develop High Strength self-compacting concrete by adopting Nan-su method, this is regarded as the simplest method of mix design.

2. To study the acceptance characteristics of SCC by measuring filling ability, passing ability and segregation resistance by using different test methods like Slump flow, Ubox, L-box, Orimet and V-funnel test.

3. To compare strength parameters (compressive strength, Tensile strength and Flexural Strength) of normal Selfcompacting concrete and fibre reinforced self-compacting concrete.

4. Analytical method formulated (7) is used to predict the failure load is examined with the experimental value observed .The formula for calculating the theoretical value is $\mathrm{P}_{\text {the }}=\mathrm{C} \mathrm{A}_{\mathrm{c}}$ $\mathrm{f}_{\mathrm{c}}+\mathrm{A}_{\mathrm{s}} \mathrm{f}_{\mathrm{y}}$, where $\mathrm{C}=1.18(7)$

$\mathrm{A}_{\mathrm{c}}=$ Area of Concrete, $\mathrm{f}_{\mathrm{c}}=$ compressive strength of concrete, $A_{s}=$ Area of steel, $f_{y}=$ Yield stress of steel.

The final objective was to evaluate the possibility of using High strength self-compacting concrete with fibres (HSSCFRC) in thin-walled HSS columns in practice. 


\section{EXPERIMENTAL PROGRAM}

\subsection{Concrete Properties}

Concrete of design strength of $70 \mathrm{MPa}$ was produced using commercially available materials with mixing using simple curing techniques. Mix design of grades was carried out in accordance to the Nan-su method .The mix designs are shown in Table 2. These grades of concrete are designated as controlled concrete. The concrete mix was obtained based on nan su method dosages: $500 \mathrm{~kg} / \mathrm{m}^{3}$ of Portland cement, $728.25 \mathrm{~kg} / \mathrm{m}^{3}$ of sand, $720.82 \mathrm{~kg} / \mathrm{m}^{3}$ of stone aggregate with maximum size $10 \mathrm{~mm}$ and. the fibres employed, with volume percentage equal to $0.5 \%$ to $2.0 \%$ by volume of concrete corresponding to $76 \mathrm{~kg} / \mathrm{m} 3$ the steel fibres used was crimped which was made from low carbon drawn flat wires. These are commercially marketed as SW 30 crimped steel fibres.length $\mathrm{L}_{\mathrm{f}}=30 \mathrm{~mm}$ and diameter $\mathrm{D}_{\mathrm{f}}=0.5 \mathrm{~mm}$ (aspect ratio $\mathrm{L}_{\mathrm{f}} / \mathrm{D}_{\mathrm{f}}=$ 60). These fibres were distributed randomly in the concrete during the mixing stage. The compressive strength of concrete mixes satisfying the workability criteria were determined. The final optimum process involved five fresh property tests like slump flow, U-box test, L-box test, J-Ring test and Orimet test were conducted to check the fresh properties of the fresh concrete (Table 3) and mix design for M-70 without and with fibres are tabulated are summarized in table no 4 The scope of the present study is limited to following: -

1. To study the behavior of CFT by using SCFRC wrt D/t and $\mathrm{L} / \mathrm{D}$ ratio.

2. The materials used in this study are aggregates of $10 \mathrm{~mm}$ downsize, sand confirming to zone II as fine aggregate, Class F-type fly ash from Raichur power plant, 53 grade Ordinary Portland Cement (Birla Super), super plasticizer (Glenium 6100).

3. The measurement of fresh properties of SCC for experimentations is limited to filling ability (slump flow, T50 slump flow, Orimet and V funnel) and passing ability (L-box and U-box) and segregation resistance ( $\mathrm{V}$ funnel at $\mathrm{T} 5$ minutes).

In order to characterize the mechanical behaviour of concrete, three cubes, three prismatic and three cylindrical specimens were prepared from each type and tested. The comparative studies have been made on the Compressive strength, Tensile strength, Flexural strength, Young's modulus of Elasticity, Poisson's ratio and Density of concrete and have been determined after 7, 28, and 56 days curing.

In these concretes a vibrator was not employed for compaction A total of 45 cubes, 45 prisms, 45 cylinders (as presented in Table 5) were prepared by adding different percentage of steel fibre and admixtures and tested after 7,28 \& 56 days of curing on a compression testing machine of $2000 \mathrm{kN}$ capacity.

\section{CFT DETAILS}

The curing of the CFT specimens was done by sealing the top surface with a polyethylene sheet, after wetting the top surface in order to avoid shrinkage of the concrete.

In order to study the behaviour of the composite CFT column, the following methodology is followed

1) 45 CFT Specimens of circular shape for M70 grades of concrete will be tested.

2) CFT will be casted using 0\%, $1 \% .1 .5 \% 2.0 \%$ fibre content for $\mathrm{D} / \mathrm{t}$ ratios.

3) Available properties such as outer nominal dia., Actual dimensions, Actual wall thickness, D/t, L/D ratio are measured. (Table 1)

4) Four strain gauges will be attached to the external surface of the steel tube at two opposing sides at each column mid height. Two strain gauges at each side measure the horizontal and longitudinal strains in the steel respectively. Dial gauges will be used to measure the lateral deflections of the column at mid height.

5) At each load increment, the strain readings and the deflection measurements were recorded .All specimens were loaded to failure

\section{TEST RESULTS AND DISCUSSIONS}

The typical structural behaviour of the tested columns was studied by the relationship between the load $P$ and the lateral deflection at mid-height. The study shows quite clearly that deflection was small during the initial part of the loading and increased rapidly near the ultimate load Furthermore, the study also shows that columns filled with plain concrete exhibit greater mid-height displacement than columns filled with FRC at any given level of load. It is seen, therefore, that the FRC filled specimen's exhibit lower flexibility compared with plain concrete filled specimens throughout the entire loaddeflection range. The reason may be attributed to the fact that FRC has higher flexural strength than plain concrete. The curve also implies that FRC filled specimens have relatively less strain gradient, as seen from the higher slope of the ascending branch, than plain concrete filled specimens until failure occurred. This was most likely influenced by the higher elastic modulus of FRC.

\section{CONCLUSIONS}

This paper presents an experimental study on circular concentrically loaded concrete filled steel tube columns, Parameters for the study included the diameter, D/t ratio of steel tube, $\mathrm{L} / \mathrm{D}$ ratio of steel tube and addition of $\%$ of steel fibre. The influence of these parameters on the confinement of the concrete core, the compression shared by the steel tube and ultimately load carrying capacity of the CFTs was investigated. 
Following are the conclusions drawn from this investigation:

1. FRC filled steel tubular columns has relatively high stiffness compared with plain concrete filled columns.

2. The ductility is found to be almost equal for both plain and FRC filled steel tubular columns.

3. The use of FRC in the steel tube results in an enhanced energy absorption capacity of the composite columns.

4. The use of FRC as a filling material increases the load bearing capacity to a much greater extent compared with that of unfilled columns and reduces the lateral displacements.
From the bare tube results it was observed that the load carrying capacity of the steel tube per unit volume decreases as the $\mathrm{D} / \mathrm{t}$ ratio increases. Hence it is suggested to fix the correct $\mathrm{D} / \mathrm{t}$ ratio in order to make optimum usage of the material.

5. Results were found to be increasing till $1.5 \%$ of steel fibres added to Self-compacting concrete and .the relationship of compressive strength to tensile strength of hardened concrete was found to be $f c=10.35 \mathrm{ft}$

Table 1: Selection criteria for $\mathrm{cft}$

\begin{tabular}{|l|l|l|l|l|l|l|l|}
\hline $\mathbf{D} \mathbf{~ m m})$ & $\mathbf{t}(\mathbf{m m})$ & $\mathbf{A}_{\mathbf{s}(\mathbf{m m} 2)}$ & $\mathbf{f}_{\mathbf{y}\left(\mathbf{N} / \mathbf{m m}^{2}\right)}$ & $\mathbf{A}_{\mathbf{c}(\mathbf{m m})} \mathbf{2}^{2}$ & $\mathbf{D} / \mathbf{t}$ & $\mathbf{L}$ & $\mathbf{L} / \mathbf{D}$ \\
\hline 48.3 & 3.2 & 453.00 & 310.00 & 1379.03 & 15.09 & 340.00 & 7.04 \\
\hline 76.1 & 4.5 & 1010.00 & 310.00 & 3536.44 & 16.91 & 340.00 & 4.47 \\
\hline 114.3 & 4.5 & 1550.00 & 310.00 & 8709.69 & 25.40 & 340.00 & 2.97 \\
\hline
\end{tabular}

Table 2: Details of basic ingredients required for SCC with fly ash as per Nan-Su Method

\begin{tabular}{|l|l|}
\hline Grade of Concrete & $\begin{array}{l}\text { SCC with Fly ash } \\
\text { P(C+F):FA:CA:W/P }\end{array}$ \\
\hline M70 & $1: 1.142: 1.13: 0.33$. \\
\hline Ingredients Required & SCCM70 \\
\hline Cement in $\mathrm{kg} / \mathrm{m}^{3}(\mathrm{C})$ & 500.00 \\
\hline Fly ash in $\mathrm{kg} / \mathrm{m}^{3}(\mathrm{~F})$ & 137.508 \\
\hline Powder content in $\mathrm{kg} / \mathrm{m}^{3}(\mathrm{P})$ & 637.508 \\
\hline F.A in $\mathrm{kg} / \mathrm{m}^{3}$ & 728.25 \\
\hline C.A in $\mathrm{kg} / \mathrm{m}^{3}$ & 720.83 \\
\hline Water in liters & 214.732 \\
\hline Super Plasticizer Dosage (SP) & 12.908 \\
\hline
\end{tabular}

Table 3: Workability Test Results with Recommended Values FOR M 70 of SCC with Fly ash

\begin{tabular}{|l|l|l|l|l|l|}
\hline Sl.no & Methods & \multirow{2}{*}{ Units } & $\begin{array}{l}\text { Test Results } \\
\text { Adopted }\end{array}$ & & \multicolumn{2}{l|}{ Recommend values } \\
\cline { 3 - 6 } & & M70 & Min & Max \\
\hline 1 & Slump Flow & Mm & 790 & 650 & 800 \\
\hline 2 & T50 slump flow & Sec & 5 & 2 & 5 \\
\hline 3 & & & & \\
\hline 4 & V Funnel & $\mathrm{Sec}$ & 10 & 6 & 12 \\
\hline 5 & U Box & $\mathrm{H}_{2} / \mathrm{H}_{1}$ & 0.85 & 0.8 & 1.0 \\
\hline 6 & J Ring & $\mathrm{H}_{2}-\mathrm{H}_{1}$ & 15 & 0 & 30 \\
\hline 7 & Orimit & $\mathrm{Mm}$ & 6 & 3 & 10 \\
\hline
\end{tabular}


Table 4: THE summarized Super Plasticizer dosage is as follows for M70 without \& WITH \% fibers:

\begin{tabular}{|l|l|l|}
\hline Super Plasticizer Dosage (SP) & Values & Units \\
\hline Fibres Vf: $0.00 \%$ & 12.908 & $\mathrm{~kg} / \mathrm{m}^{3}$ \\
\hline Fibres Vf: $0.50 \%$ & 14.79 & $\mathrm{~kg} / \mathrm{m}^{3}$ \\
\hline Fibres Vf: $1.00 \%$ & 18.49 & $\mathrm{~kg} / \mathrm{m}^{3}$ \\
\hline Fibres Vf: $1.50 \%$ & 23.43 & $\mathrm{~kg} / \mathrm{m}^{3}$ \\
\hline Fibres Vf: $2.00 \%$ & 29.58 & $\mathrm{~kg} / \mathrm{m}^{3}$ \\
\hline
\end{tabular}

Table 5: properties of hardened concrete

\begin{tabular}{|c|c|c|c|c|c|c|c|c|c|}
\hline \multirow[b]{2}{*}{ Strength } & \multicolumn{3}{|c|}{ SCCM70 (0\%) } & \multicolumn{3}{|c|}{ SCCM70 (0.5\%) } & \multicolumn{3}{|c|}{ SCCM70 (1.0\%) } \\
\hline & 7 & 28 & 56 & 7 & 28 & 56 & 7 & 28 & 56 \\
\hline $\begin{array}{l}f_{c} \text { in } \\
M p a\end{array}$ & 43 & 62. & 63. & 45 & 65.77 & 66.5 & 48. & 68.00 & 69.0 \\
\hline $\begin{array}{l}f_{t, \text { in }} \\
\text { Mpa }\end{array}$ & 4.4 & 5.81 & 5.9 & 4.6 & 6.10 & 6.10 & 4.8 & 6.50 & 6.50 \\
\hline $\begin{array}{l}f_{b t,} \text { in } \\
M p a\end{array}$ & 5.6 & 7.25 & 7.4 & 5.8 & 7.30 & 7.40 & 6.0 & 7.40 & 7.50 \\
\hline $\begin{array}{l}\text { E, in } \\
\text { Gpa }\end{array}$ & - & 35.8 & -- & -- & 35.8 & -- & -- & 36.00 & -- \\
\hline$\mu$ & - & 0.17 & -- & -- & 0.17 & -- & -- & 0.16 & --- \\
\hline $\begin{array}{l}\gamma_{d} \text { in } \\
K N / m^{3}\end{array}$ & ---- & 24.5 & --- & --- & 24.50 & -- & -- & 25.00 & --- \\
\hline
\end{tabular}

\begin{tabular}{|l|l|l|l|l|l|l|}
\hline \multirow{2}{*}{ Strength } & \multicolumn{3}{|c|}{ SCCM70 (1.50\%) } & \multicolumn{3}{c|}{ SCCM70 (2.0\%) } \\
\cline { 2 - 7 } & 7 & 28 & 56 & 7 & 28 & 56 \\
\hline$f_{c}$ in Mpa & 49 & 70.22 & 70.70 & 44 & 64.00 & 64 \\
\hline$f_{t, \text { in } M p a}$ & 5.0 & 6.70 & 6.78 & 4.5 & 6.00 & 6.10 \\
\hline$f_{b t, \text { in } M p a} 6.2$ & 7.80 & 7.9 & 5.5 & 7.20 & 7.30 \\
\hline
\end{tabular}

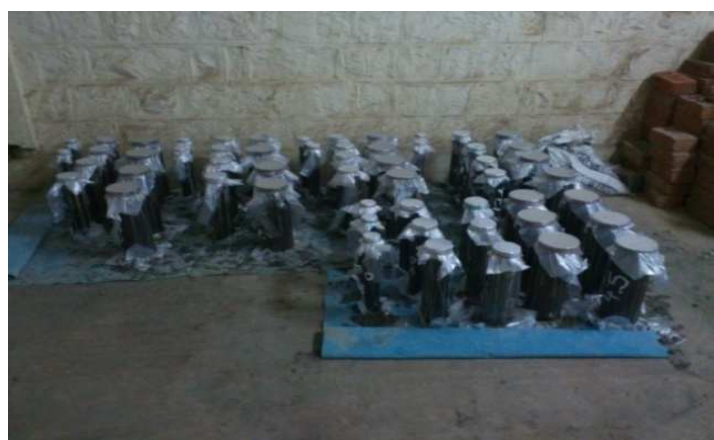

Fig 1 Cft Specimens

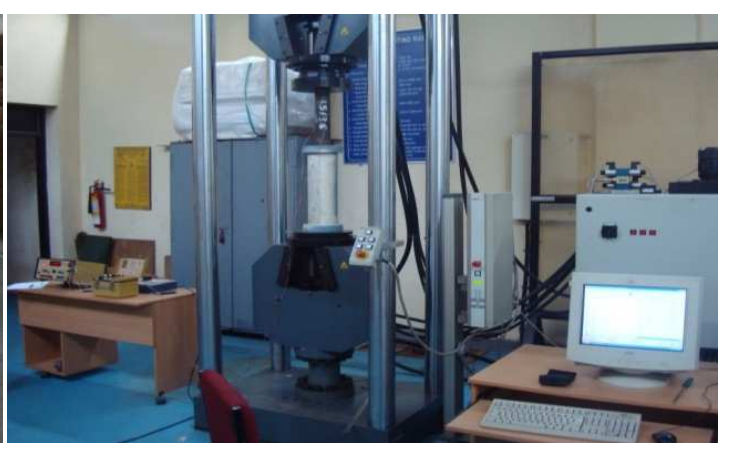

Fig 2: Testing Of Cft 
Table 6: Comparison of load carrying capacity of CFTs

\begin{tabular}{|l|l|l|l|l|l|l|l|}
\hline Specimens & $\begin{array}{l}\text { Outer } \\
\text { Diameter(mm) }\end{array}$ & $\begin{array}{l}\text { Wall } \\
\text { Thickness(t) }\end{array}$ & D/t & L & L/D & Pexp & Ptheo \\
\hline D2M7C1 & 48.3 & 3.2 & 15.09 & $340 \mathrm{~mm}$ & 7.04 & 240.00 & 241.68 \\
\hline D2M7C10.5 & 48.3 & 3.2 & 15.09 & $340 \mathrm{~mm}$ & 7.04 & 241.00 & 247.45 \\
\hline D2M7F1,1 & 48.3 & 3.2 & 15.09 & $340 \mathrm{~mm}$ & 7.04 & 246.00 & 251.09 \\
\hline D2M7F1.5,1 & 48.3 & 3.2 & 15.09 & $340 \mathrm{~mm}$ & 7.04 & 249.00 & 254.70 \\
\hline D2M7F2.0,1 & 48.3 & 3.2 & 15.09 & $340 \mathrm{~mm}$ & 7.04 & 241.00 & 244.57 \\
\hline D3M7C1 & 76.1 & 4.5 & 16.91 & $340 \mathrm{~mm}$ & 4.47 & 565.00 & 572.74 \\
\hline D3M7F0.51 & 76.1 & 4.5 & 16.91 & $340 \mathrm{~mm}$ & 4.47 & 579.00 & 587.56 \\
\hline D3M7F11 & 76.1 & 16.91 & $340 \mathrm{~mm}$ & 4.47 & 580.00 & 596.86 \\
\hline D3M7F1.5,1 & 76.1 & 4.5 & 16.91 & $340 \mathrm{~mm}$ & 4.47 & 600.00 & 606.13 \\
\hline D3M7F2.0,1 & 76.1 & 4.5 & 25.40 & $340 \mathrm{~mm}$ & 2.97 & 1115.00 & 1119.96 \\
\hline D47C1 & 114.3 & 4.5 & 25.40 & $340 \mathrm{~mm}$ & 2.97 & 1145.00 & 1156.45 \\
\hline D4M7F0.51 & 114.3 & 4.5 & 25.40 & $340 \mathrm{~mm}$ & 2.97 & 1146.00 & 1179.37 \\
\hline D4M7F1.01 & 114.3 & 4.5 & 25.40 & $340 \mathrm{~mm}$ & 2.97 & 1202.18 & 1202.18 \\
\hline M7F1.5,1 & 114.3 & 4.5 & 25.40 & $340 \mathrm{~mm}$ & 2.97 & 1134.00 & 1138.26 \\
\hline D4M7F2.0,1 & 114.3 & 4.5 & 3.5 & $\mathrm{C}-\mathrm{Con}$ \\
\hline
\end{tabular}

D2- 48.3mm, D3-78.1 mm D4-114.3mm.diameter tube, M7-M70 Concrete C-Control mix, FXY-fibre, X-Percentage of fibre Yspecimen number (Average of 3 Specimens)

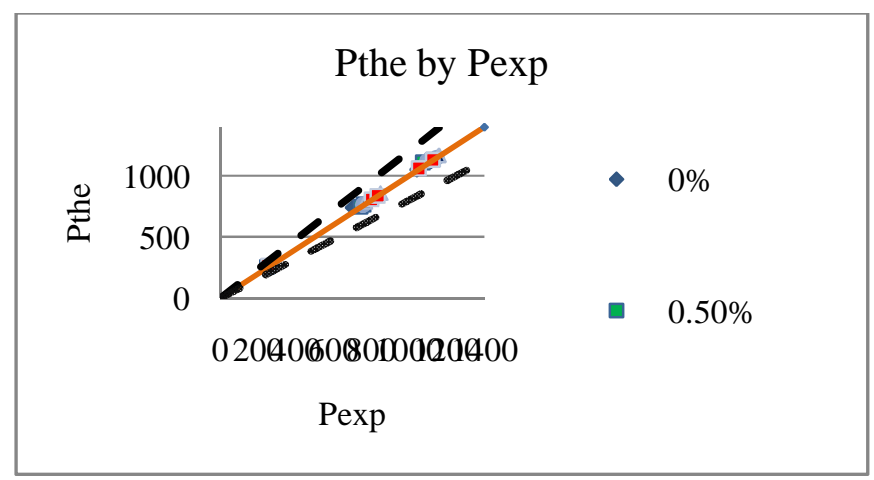

\section{ACKNOWLEDGMENTS}

Authors hereby acknowledge the Management of Sir MVIT, BCE \& GCE and Dr M.S.Indira, Principal Sir MVIT, Bangalore, Dr Noor Ahmed, Principal of Brindavan college of Engineering, Dr Mohamed Haneef, Principal, Ghousia College of Engineering, Ramanagaram and Dr. Ramesh Babu, Additional director, EVRC Division, CPRI, Bangalore, for their continuous support rendered during this research work.

\section{REFERENCES}

[1] M Mazloom, A Ranjbar, "Relation between the workability and strength of self-compacting concrete". $35^{\text {th }}$ Conference on OUR WORLD IN CONCRETE \& STRUCTURES: 25 - 27 August 2010, Singapore.

[2] Bertil Persson, "A Comparison between Mechanical Properties of Self compacting concrete and Normal concrete" Cement and Concrete Research, 31(2001), pp 193-198
[3] P.K. Gupta, S.M. Sarda, M.S. Kumar, "Experimental and computational study of concrete filled steel tubular columns under axial loads", Journal of Constructional Steel Research 63 (2007) 182-193

[4] Lin-Hai Han, Guo-Huang Yao, Xiao-Ling Zhao "Tests and calculations for hollow structural steel (HSS) stub columns filled with self-consolidating concrete (SCC)", Journal of Constructional Steel Research 61 (2005) 1241-1269

[5] Georgios Giakoumelis, Dennis Lam "Axial capacity of circular concrete-filled tube columns", Journal of Constructional Steel Research 60(2004) 1049-1068

[6] Stephen P.Schneider "Axially Loaded Concrete-Filled Steel Tubes, Journal of Structural Engineering No: 124 .No: 10, October 1998/1125-1138

[7] Muthu.K.U, Ravi Kumar.H. And. Kumar N.S,"Computational Study of Concrete Filled Steel Tubular Columns Under Axial Loads", Proceedings of International Conference on Emerging Trends in Engineering, Nitte, India, May 4th-5th 2011 page 795-799.

[8] H. Ravi Kumar K.U.Muthu and N.S.Kumar *Concrete filled steel tubular columns-a critical review" Cement and Concrete Composites Elixir Cement \& Con. Com, 45 (2012) 8034-8038 